\title{
Opinion paper: Beef, climate change and a slice of common sense
}

\author{
T. Haniotis ${ }^{\dagger}$ \\ Directorate C - Strategy, Simplification and Policy Analysis, DG Agriculture and Rural Development, European Commission, L130 9/112, B-1049 Brussels, Belgium
}

\section{The news}

I think it can be fair to say that beef has not had its best days lately. From the LANCET report linking diets to health and sustainability (Willett et al., 2019) to the recent food safety scandal in Poland, the beef sector is once more on the receiving end of news headlines.

Yet, while the second issue is a blatant violation of the law (the solutions to which are within easy reach provided the will exists), the direct linkage of beef production and consumption to climate change, the issue coveted by the former, is less straightforward. There is no doubt in my mind that the livestock sector plays a crucial role in any strategy that seriously wants to address climate change. This, though, requires placing the big picture and basic facts into perspective.

This is more so since the current debate about beef and its role in climate change bears similarities with the heated debate about food security in the aftermath of the financial and commodity crisis a decade ago. Then, as now, one single factor (biofuels then, beef now) was expected to address the issue at stake.

At that time, many argued that banning biofuels would have solved the shortage of food and high price problem, and strategic stocks would have saved the developing world from the vagaries of price volatility. Now, beef seems to have assumed the disproportionate burden of proof on climate action, excluding from this process many other significant and untouched factors that are not so trivial. However, should this be the case?

\section{The big picture}

Since the beginning of time, man has been faced with five basic needs - food, shelter, clothing, movement and the energy to do it all. Innovative solutions in achieving these have always been of great benefits for our species but, unfortunately, to the great cost and damage to other species and the planet. Faced with this reality comes the increased recognition, at least in words if not in actions, that our future has to be sustainable, if it is to be at all. Current sustainability challenges, exemplified by climate change, help push for

\footnotetext{
${ }^{\dagger}$ E-mail: anastassios.haniotis@ec.europa.eu
}

greater urgency in the search for solutions that could contribute in changing things. To be sustainable themselves, such solutions need to avoid the search for quick fixes.

A little done by many will be of greater benefit than a lot by a few

Reversing the path towards the abyss will firstly require a slowdown, before the reversal of current trends - there is simply no other way, and the sooner this is publicly acknowledged the better. This is not a betrayal of sustainability. It is a recognition of the fact that a little done by many will be of greater benefit than a lot by a few, opening the way for achieving a great extent by all.

Such solutions should reflect a proportional contribution of action and progress in all the above five basic needs, with the understanding that proportional does not mean equal as the underlying parameters differ.

\section{The facts}

What is feasible starts from the recognition of what already exists today. Yet again, basic facts are often side-lined in the public debate. Tables 1 and 2 summarise world annual percentage rates of growth for major crop and livestock products, shedding light on some of the basic facts so often misrepresented in the public debate. Based on the OECD database, these rates of growth are broken down here into sub-periods reflecting major factors influencing food production patterns (from the 'green' revolution and the first two energy crises to the most recent impacts from trade liberalisation and the post-financial crisis periods).

The tables point out the very diverse growth (and thus footprint) of various livestock and crop products during the past half-century. In addition to these facts, others also point out, in a non-exhaustive manner, the following:

- Annual beef world consumption grew during the last decade at $0.6 \%$, half the corresponding growth rate of world population (1\%). The only other major food product with lower growth than world population was wheat, at $0.8 \%$.

- World pig meat consumption grew at twice the annual rate of growth of beef, poultry at four times this rate, thus being the main drivers (together with dairy) of the strong maize and 
Haniotis

Table 1 World annual rates of growth in livestock consumption (\%)

\begin{tabular}{lcccccrr}
\hline \hline Period & Population (\%) & Beef (\%) & Pig meat (\%) & Poultry (\%) & Sheep and goat (\%) & Butter (\%) & Cheese (\%) \\
\hline $1961-73$ & 2.0 & 2.9 & 4.3 & 5.8 & 0.9 & 1.5 & 4.4 \\
$1973-85$ & 1.8 & 2.0 & 3.3 & 4.9 & 2.1 & 1.7 & 3.3 \\
$1985-97$ & 1.6 & 1.0 & 2.1 & 5.5 & 1.9 & 2.0 & 1.2 \\
$1997-09$ & 1.2 & 1.2 & 2.5 & 4.0 & 1.1 & 2.2 & 1.4 \\
$2009-17$ & 1.0 & 0.6 & 1.2 & 2.3 & 2.2 & \\
\hline \hline
\end{tabular}

Source: European Commission - Directorate-General for Agriculture (DG AGRI) based on OECD data - A graphical representation of these facts was in the annex of the presentation at the World Science Forum, which took place in Jordan in November 2017; an updated version of the presentation which incorporates information that became available since can be viewed online (Haniotis, 2019).

Table 2 World annual rates of growth in crop consumption (\%)

\begin{tabular}{lccccccc}
\hline \hline Period & Population (\%) & Wheat (\%) & Maize (\%) & Rice (\%) & Soybeans (\%) & Sugar (\%) & Palm oil (\%) \\
\hline $1961-73$ & 2.0 & 3.8 & 3.7 & 3.8 & 6.2 & 3.4 & 4.2 \\
$1973-85$ & 1.8 & 3.0 & 2.4 & 2.9 & 5.0 & 2.4 & 9.6 \\
$1985-97$ & 1.6 & 1.1 & 2.6 & 1.7 & 3.7 & 2.0 & 7.0 \\
$1997-09$ & 1.2 & 1.2 & 2.9 & 1.7 & 4.0 & 1.6 & 8.1 \\
$2009-17$ & 1.0 & 0.8 & 3.9 & 1.3 & 4.7 & 1.4 & 6.4 \\
\hline \hline
\end{tabular}

Source: European Commission - Directorate-General for Agriculture (DG AGRI) based on OECD data - A graphical representation of these facts was in the annex of the presentation at the World Science Forum, which took place in Jordan in November 2017; an updated version of the presentation which incorporates information that became available since can be viewed online (Haniotis, 2019).

soybean growth. Palm oil, present in so many processed food items, grew at 10 -fold the rate of growth of beef.

- Half of the world cattle herd is concentrated in just three countries - India, Brazil and China, thus requiring a significant contribution from their part for global impact.

- $\quad$ EU extensive meat production systems may not be the most efficient in the world when assessed only on economic costs, but are clearly more environmentally efficient than most, thus rendering the trade-offs from its substitution environmentally costly from a global perspective.

- $\quad$ EU meat production is also at the forefront of increasing animal welfare and health legislation, despite already having some of the highest standards worldwide (something that allows immediate reactions to the unfortunate and irresponsible actions of some).

\section{The need for balance}

Food is central in the search for sustainable solutions to address climate change, and meat is central in food. Yet understanding basic food facts is also essential. Not all meat production methods have the same environmental impact, be it on land, water, soil, biodiversity or air. Not all shifts in diets have the same economic or social effect, especially since tastes and preferences are not just influenced and determined by income and price, but also by culture. Not all suggested alternatives are feasible: the economics are not always there for various reasons. Local improvement in environmental costs is often associated with greater global negative externalities; resistance to change is often underestimated, at a great subsequent cost.
This is why the frontal attack in just one area of potentially unsustainable practices - beef - is misleading. We are continually told 'Stop eating beef and we will save the planet'. Really? Then how do we explain the fact that, despite eating less beef in the EU (beef production, per capita consumption and exports today are almost a third lower of what it was 25 years ago), there is still so much more to do when it comes to cutting emissions?

Could it be that articles that only consider emissions often omit carbon sequestration and ignore the carbon emission problem that would come from converting grassland to alternative food products, overstate the problem?

Could it be that the easiness in attacking a sector characterised by slow adjustment, and its thus resulting conservative attitude, helps us hide some other uncomfortable truths?

Could it be the fact that the great majority of us are city dwellers of this world, and increasingly with no farming background or concept of farming dynamics? (I belong to this group, for those wondering).

We feel much more comfortable when an activity so far away from our daily life, such as farming, has to assume a disproportionate burden of adjustment, while we can increase our daily activities and consumption in other fashionable items. Other activities closer to our daily life - fashionable food patterns (e.g. sushi or plant-based drinks), shelter (e.g. 'sustainable' furniture), clothing (whose over consumption and waste is never discussed), energy (where the increase in social media use eats up an ever growing part of the increase in renewable energy), movement patterns (from air miles to car journeys) - somehow escape such attention. 
Should not these other basic needs receive the same level of attention?

To conclude, beef, as all sectors, has to assume its share in addressing what, in my view, will be the continuous challenge of the $21^{\text {st }}$ century, of adapting to and mitigating climate change. The only thing I am claiming again (adding the usual caveat that this is strictly personal) is that, if we want to be politically correct, we had better start by being factually correct.

\section{Acknowledgements}

The author is the Director of the Directorate C - Strategy, Simplification and Policy Analysis in the Directorate General for Agriculture and Rural Development of the European Commission. The views expressed in this document are those of the author. A first version of this paper was posted on Linkedln at https://www.linkedin.com/today/author/tassoshaniotis-72791466 in February 2019.

\section{References}

Haniotis T 2019. Science and food security: How to feed the world sustainably and equitably. Retrieved on 8 February 2019 from https://www.slideshare.net TassosHaniotis/science-and-food-security-how-to-feed-the-world-sustainablyand-equitably

Willett W, Rockström J, Loken B, Springmann M, Lang T, Vermeulen S, Garnett T, Tilman D, DeClerck F, Wood A, Jonell M, Clark M, Gordon LJ, Fanzo J, Hawkes C Zurayk R, Rivera JA, De Vries W, Majele Sibanda L, Afshin A, Chaudhary A, Herrero $M$, Agustina R, Branca $F$, Lartey $A$, Fan $S$, Crona B, Fox E, Bignet V, Troell M, Lindahl T, Singh S, Cornell SE, Srinath Reddy K, Narain S, Nishtar S and Murray CJL 2019. Food in the Anthropocene: the EAT-Lancet Commission on healthy diets from sustainable food systems. The Lancet 393, 447-492. 